\title{
Fibroblast Growth Factor 8 Organizes the Neocortical Area Map and Regulates Sensory Map Topography
}

\author{
Stavroula Assimacopoulos, Tina Kao, Naoum P. Issa, and Elizabeth A. Grove \\ Department of Neurobiology, University of Chicago, Chicago, Illinois 60637
}

The concept of an "organizer" is basic to embryology. An organizer is a portion of the embryo producing signals that lead to the creation of a patterned mature structure from an embryonic primordium. Fibroblast growth factor 8 (FGF8) is a morphogen that disperses from a rostromedial source in the neocortical primordium (NP), forms a rostral-to-caudal (R/C) gradient, and regulates embryonic and neonatal R/C patterns of gene expression in neocortex. Whether FGF8 also has organizer activity that generates the postnatal neocortical area map is uncertain. To test this possibility, new sources of FGF8 were introduced into the mouse NP with in utero microelectroporation at embryonic day 10.5, close to the estimated peak of area patterning. Results differed depending on the position of ectopic FGF8. Ectopic FGF8 in the caudalmost NP could duplicate somatosensory cortex (S1) and primary visual cortex (V1). FGF8 delivered to the midlateral NP generated a sulcus separating rostral and caudal portions of the NP, in effect creating duplicate NPs. In the caudal NP, ectopic FGF8 induced a second, inclusive area map, containing frontal cortex, S1, V1, and primary auditory areas. Moreover, duplicate S1 showed plasticity to sensory deprivation, and duplicate V1 responded to visual stimuli. Our findings implicate FGF8 as an organizer signal, and its source in the rostromedial telencephalon as an organizer of the neocortical area map.

\section{Introduction}

Different neocortical functions such as visual perception, motor control and planning are allocated to specialized areas, which form a species-specific area map across neocortex. How the area map is set up in development is far from understood, but substantial advances have been made (Rakic, 1988; CohenTannoudji et al., 1994; Miyashita-Lin et al., 1999; Bishop et al., 2000; Mallamaci et al., 2000; Crossley et al., 2001; FukuchiShimogori and Grove, 2001; Muzio et al., 2002; Garel et al., 2003; Hamasaki et al., 2004; Lukaszewicz et al., 2005; Shimogori and Grove, 2005; Armentano et al., 2007; Sahara et al., 2007; Cholfin and Rubenstein, 2008; Toyoda et al., 2010). Progress includes evidence that fibroblast growth factor 8 (FGF8) is a neocortical morphogen (Fukuchi-Shimogori and Grove, 2001; Garel et al., 2003; Huffman et al., 2004; Toyoda et al., 2010). FGF8 disperses from the rostromedial telencephalon to form a rostral-to-caudal $(\mathrm{R} / \mathrm{C})$ gradient throughout the neocortical primordium (NP), and cells read out their R/C position from the local FGF8 concentration (Toyoda et al., 2010). FGF8 regulates graded expression of cortical developmental control genes, including Emx2 and Couptf1/Nr2f1 (Crossley et al., 2001; Fukuchi-Shimogori and Grove, 2003; Garel et al., 2003; Storm et al., 2006; Cholfin and Rubenstein, 2008; O'Leary and Sahara, 2008). The function of

\footnotetext{
Received Jan. 5, 2012; revised March 14, 2012; accepted March 30, 2012.

Author contributions: S.A., N.P.I., and E.A.G. designed research; S.A. and T.K. performed research; N.P.I. contributed unpublished reagents/analytic tools; S.A., N.P.I., and E.A.G. analyzed data; E.A.G. wrote the paper.

This work was supported by NIH Grant R01 HD42330 (E.A.G.). We thank C. W. Ragsdale for his helpful comments on this manuscript.

Correspondence should be addressed to Elizabeth A. Grove, University of Chicago, Department of Neurobiology, 947 East 58th Street, Chicago, IL 60637. E-mail: egrove@bsd.uchicago.edu.

N. P. Issa's present address: Department of Neurology, University of Chicago, Chicago, Illinois 60637.

DOI:10.1523/JNEUROSCI.0071-12.2012

Copyright $\odot 2012$ the authors $\quad 0270-6474 / 12 / 327191-11 \$ 15.00 / 0$
}

FGF8 in the NP is therefore reminiscent of the role of FGF8 in patterning the midbrain and hindbrain from a source at the isthmus (Sato et al., 2004; Nakamura et al., 2008; Chen et al., 2009).

Most readouts of FGF8 activity as a morphogen have been transient gene expression patterns in the NP and neonatal neocortex. Such findings are insufficient to demonstrate that FGF8 is an organizing signal for the area map. An organizer generates the mature structure observed in a given tissue. Traditionally, grafting into an embryo a second candidate organizer, roughly opposite to its endogenous position, is used to reveal organizer activity. Thus, grafting a second body axis organizer, the dorsal blastopore lip, into the ventral side of an amphibian gastrula generates twinned embryos (Spemann and Mangold, 1924). Similarly, a second zone of polarizing activity (ZPA) placed rostrally in a limb bud duplicates digits (Summerbell, 1981). In the mouse embryo, where transplantation is difficult, a comparable experiment introduces a second source of a candidate organizer signal.

Ectopic FGF8 introduced by in utero microelectroporation has been shown to duplicate somatosensory cortex (S1) barrels (Fukuchi-Shimogori and Grove, 2001), but this result has been inconsistent (Sahara et al., 2007). Moreover, an organizer signal should duplicate a richer pattern of tissue fates. For example, an FGF8-coated bead transforms chick caudal forebrain into an ectopic midbrain with correctly formed duplicate structures (Crossley et al., 1996). A possibility is that ectopic FGF8 was introduced into the NP too late (Shimogori and Grove, 2005), when the NP was not competent to generate more complete area duplications. We consequently refined in utero microelectroporation to allow gene transfection near the estimated peak of area patterning (Shimogori and Grove, 2005; Toyoda et al., 2010). Ectopic FGF8 introduced at this stage shows robust organizer activity in neocortex. 


\section{Materials and Methods}

Mice. Timed pregnant CD- 1 or C57BL/6 mice were obtained from the University of Chicago Transgenic Facility. Noon of the day on which a vaginal plug was seen was termed embryonic day 0.5 (E0.5). Embryos and mouse pups of both sexes were used in this study. The Institutional Animal Care and Use Committee of the University of Chicago approved all protocols, and mice were used according to National Institutes of Health guidelines.

In utero microelectroporation. cDNAs encoding mouse FGF8 isoform b (FukuchiShimogori and Grove, 2001) and tdTomato (Genove et al., 2005) were cloned into the pEFX expression vector (Agarwala et al., 2001). Microelectrodes were fabricated as follows: for platinum electrodes, $10-\mathrm{cm}$-long pieces of platinum wire (diameter, $0.125 \mathrm{~mm}$; Goodfellow Cambridge Limited) were coiled and soldered at one end to gold-plated female connector pins. The platinum wires were inserted into glass capillaries (A-M Systems, catalog \#629000) and connectors permanently fixed to the capillaries with adhesive (commercially available hot glue). Tips of the exposed wires were tapered to fine points, $20-40 \mu \mathrm{m}$, with sandpaper. Exposed electrodes were insulated with nail polish, and $200 \mu \mathrm{m}$ of insulation was removed from each tip with acetone. Tungsten microelectrodes were purchased ready-made (FHC, catalog item UEWMEGSEDNNM) and inserted into glass capillaries, male connector pins were affixed to the capillaries with adhesive, and exposed electrodes were insulated with nail polish. Three hundred micrometers of insulation were stripped from the tips using acetone. Timed pregnant mice were anesthetized intraperitoneally with sodium pentobarbital $(50 \mu \mathrm{g}$ per gram body weight). A $2 \mathrm{~cm}$ midline incision was made in the abdominal wall along the linea alba. The right uterine horn was gently lifted and exposed; each embryo was visualized through the uterine wall by back lighting the uterus with a flexible fiber-optic bundle attached to an ACE Light Source (Schott-Fostec). A finely tapered micropipette (20-40 $\mu$ m outer diameter) containing DNA plasmid solution $(1 \mu \mathrm{g} / \mu \mathrm{l}$ of each expression construct plus $1 \%$ fast green dye) was inserted into the left cerebral ventricle of each embryo, and $\sim 0.5 \mu \mathrm{l}$ of DNA solution was injected into the lumen. The tungsten electrode (anode) was introduced into the left cerebral ventricle and the platinum electrode (cathode) positioned outside the brain within the amniotic sac. A series of three biphasic square-wave pulses at 7.5 V and $100 \mathrm{~ms}$ duration per pulse were delivered with an A-M Systems Isolated Pulse Stimulator Model 2100. The right uterine horn was placed back into the abdomen, and the procedure was repeated with the left horn. In each experiment, pairs of electroporated expression constructs encoded either Fgf8 isoform b (the most effective isoform of FGF8 in patterning at the isthmus) (Sato et al., 2004) and tdTomato, or, as controls, 3 XVenus and tdTomato. In utero electroporation of control genes has no obvious effect on tissue growth and development or on the expression of any of hundreds of genes we have examined over 10 years. To provide additional confirmation, 28 brains electroporated with $3 X V$ Venus and tdTomato at E10.5, showing a strong electroporation site at postnatal day 6 (P6), were processed for serotonin transporter immunoreactivity (SERT-IR). Even very large electroporation sites covering most of the neocortex failed to alter the area map or the size of the electroporated hemisphere.

Determining the site and strength of Fgf8 electroporation. Brains were coelectroporated with Fgf8 and tdTomato. Previously (Toyoda et al., 2010), we determined with double fluorescence/immunofluorescence (IFL; tdTomato fluorescence/FGF8 IFL; $n=5$ ) and with multicolor fluorescent in situ hybridization (FISH; $n=15$ ) that the sites of tdTomato
Sert-IR -
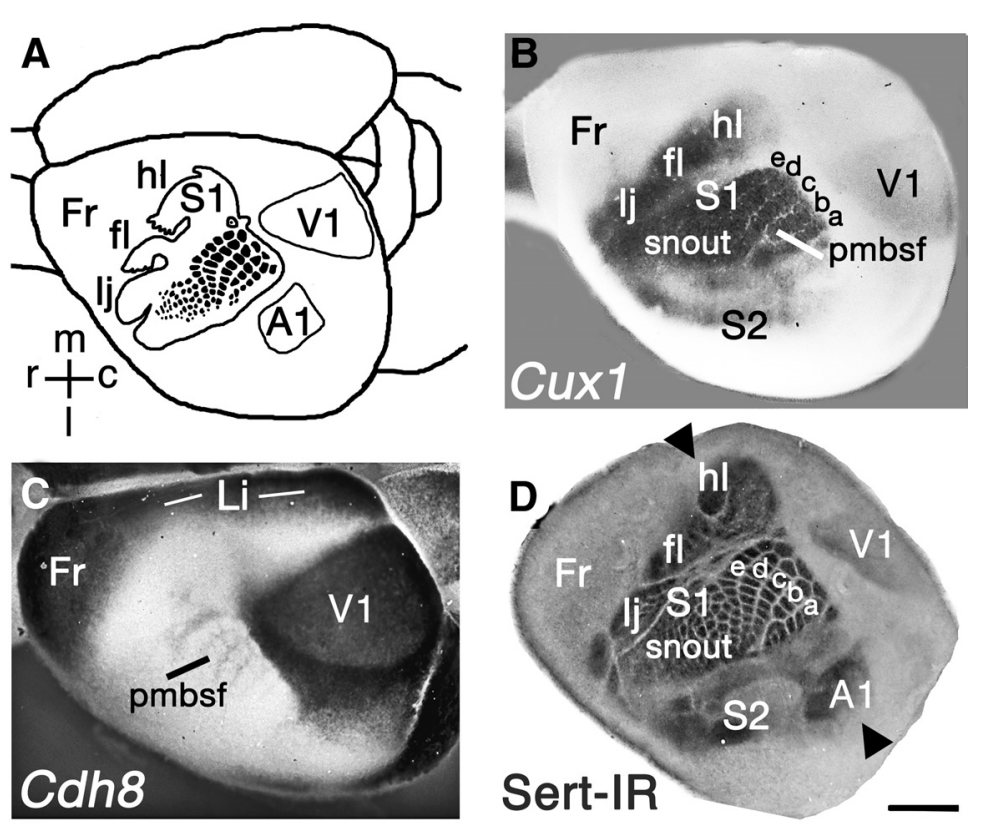

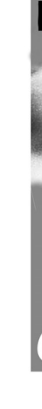

Figure 1. The mouse area map at P6.A, Schematic of a brain at P6, in dorsolateral view, showing the positions of Fr, $S 1$, V1, and A1. S1 hl, fl, and lj representations are rostral to the whisker barrel fields (barrels in black). Rostral ( $\mathrm{r}$ ), caudal (c), medial (m), and (I) in the map are indicated at lower left; these directions are roughly the same for $\boldsymbol{B}-\boldsymbol{D} . \boldsymbol{B}, \boldsymbol{C}, \boldsymbol{C u x} 1$ and Cdh8 expression is A1 lie along a line running rostromedial to caudolateral in the hemisphere ( $\boldsymbol{D}$, arrowheads). $(\boldsymbol{C}$ h 8 expression marks the wedge of frontal cortex, which is negative for SERT-IR $(\boldsymbol{C})$. These area shapes and relationships help identify particular areas in maps with , 1 mm. fl, forelimb; hl, hindlimb; lj, lower jaw; Li, limbic cortex.

and Fgf8 gene or protein expression overlapped completely $20-24 \mathrm{~h}$ after coelectroporation. The size of the tdTomato and Fgf 8 coelectroporation site, together with the density of cells labeled for tdTomato/Fgf8 gene or protein expression, which was also correlated, were taken to reflect the "strength" of electroporation (Toyoda et al., 2010). We further coelectroporated brains at E10.5; collected them at E12.5, E13.5, E14.5, or E15.5; assessed them for tdTomato fluorescence; and sectioned and processed the brains for $F g f 8$ expression with ISH $(n>100)$. Overlapping sites of $F g f 8$ and tdTomato expression were seen for $4-5 \mathrm{~d}$ after coelectroporation. During this period, Fgf8- and tdTomato-electroporated cells did not migrate substantially from the main site of electroporation (Toyoda et al., 2010). Electroporation provides only a transient transfection, however, and with cell division, an electroporated expression vector is diluted out. Consequently, after E15.5, ectopic Fgf8 expression diminished. Moreover, FGF8 protein is rapidly removed by endocytosis and degradation, required to form the FGF8 morphogen gradient (Scholpp and Brand, 2004), making FGF8 IFL a poor choice for determining the original electroporation site at later ages. The longer perdurance of tdTomato protein, nonetheless, gave clear tdTomato fluorescence until at least P6. In the present study, therefore, the relative R/C and medial-tolateral (M/L) position and the strength of the initial Fgf8/tdTomato electroporation site in each P6 brain were inferred from the position and strength of tdTomato fluorescence. The term "strong electroporation," used below in Results, implies that the size of the electroporation site was equivalent to those illustrated in Figures 2, 4, and 7, and that fluorescent cells densely filled the site. "Weak" electroporation implies smaller sites more sparsely filled with fluorescent cells. Measuring absolute levels of FGF8 present 12-24 h after Fgf8 electroporation would help determine the relationship between specific levels of ectopic FGF8 and their outcomes for the cortical area map. Unfortunately, however, we have yet to find an antibody to FGF8 that works in Western blots.

Brains were viewed with a Leica dissection microscope immediately after dissecting them from the skull. The site of tdTomato in each brain was captured in photographs of the whole brain using an AxioCam MRm 

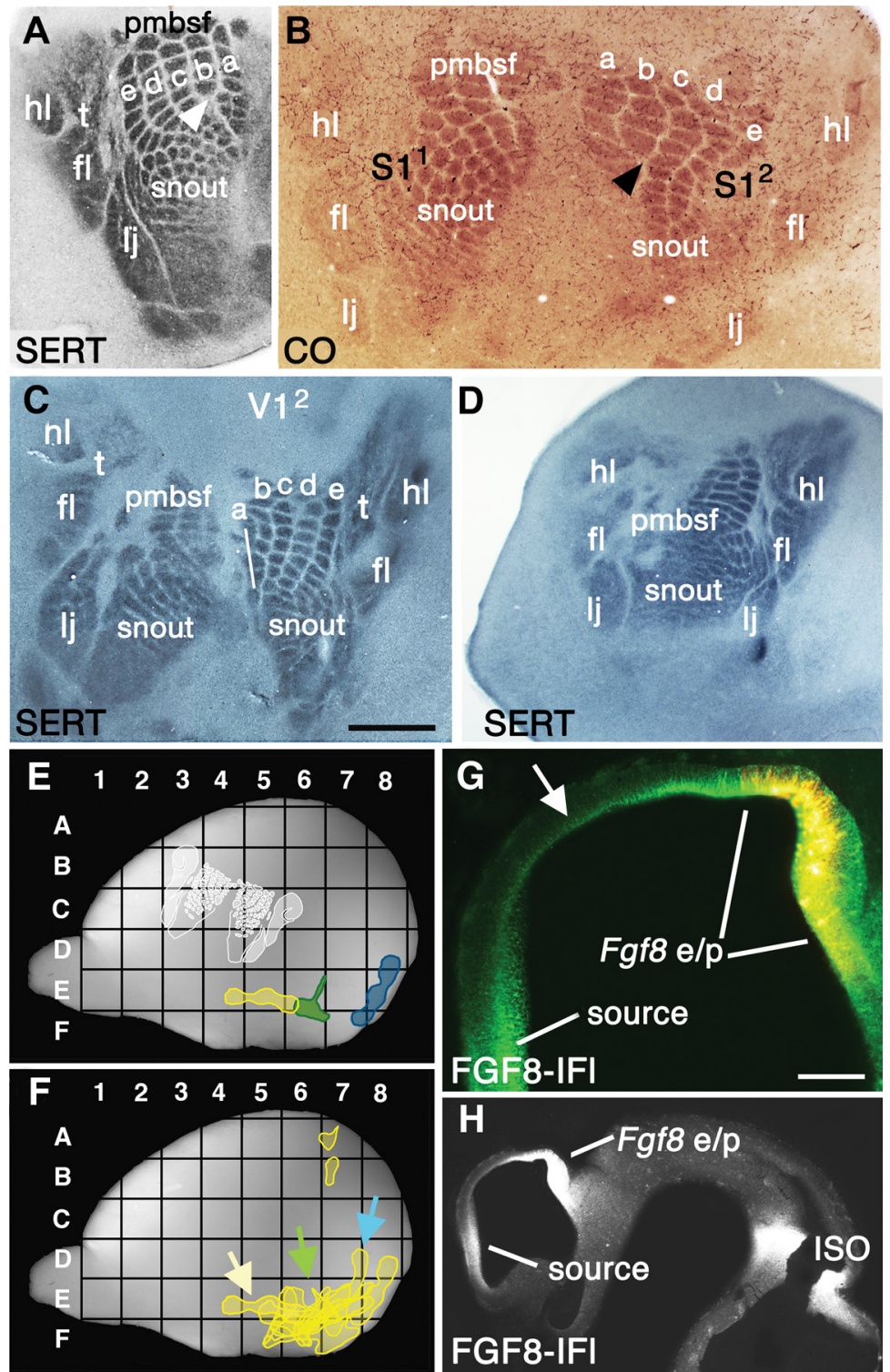

Figure 2. Far caudal electroporation of Fgf8 induces duplication of S1. A-D, Sections through flattened P6 cortices stained for SERT-IR or cytochrome oxidase (CO), rostral to the left. $\boldsymbol{E}, \boldsymbol{F}$, Schematics of electroporation sites superimposed on a standard P6 hemisphere in lateral view, rostral to the left. $G, H$, High and low magnification of FGF8 IFL in a brain with endogenous and ectopic FGF8 sources. A control brain section $(\boldsymbol{A})$, and sections from three brains electroporated with Fgf8 atE10.5 (B-D) are shown. Normally, the hl, fl, and ljsubfields are rostral to the pmbsf and the snout barrel subfield, and within the pmbsf five barrel rows labeled a- e run caudolateral to rostromedial $(\boldsymbol{A})$. Native $S 1$ is shown on the left, and duplicate $S 1$ on the right $(\boldsymbol{B}-\boldsymbol{D})$. $\boldsymbol{B}$, Duplication of $S 1$. Duplicate $S 1\left(S 1^{2}\right)$ is reversed along the $R / C$ axis relative to $S 1^{1}$. The arrowhead indicates row b in $S 1^{2}$ (a short, normally caudal row with four barrels) as a landmark. C, Duplication with some native $S 1^{1}$ barrels absent. $\boldsymbol{D}$, Duplication with the pmbsf seen only in $S 1^{2}$, and the snout barrel fields of $S 1^{1}$ and $S 1^{2}$ fused, although $\mathrm{hl}, \mathrm{fl}$, and $\mathrm{I}$ subfields are duplicated. $\boldsymbol{E}$, Electroporation sites that induced duplications in $\boldsymbol{B}-\boldsymbol{D}$ are blue, green, and yellow, respectively; the white outline indicates the approximate position of native and duplicate $S 1$ relative to electroporation sites. $\boldsymbol{F}$, A plot of 12 of 24 electroporation sites that led to S1 duplications; 10 are caudolateral, and two outliers are caudomedial. The most caudal electroporation sites (blue arrow) produced the most complete duplicate S1s; more rostral sites (green and yellow arrows) generated S1 duplications lacking sections of caudal subfields. G, One sagittal section through an E11 brain electroporated caudally at E10. The endogenous and ectopic, caudal sources of FGF8 generate a double gradient of FGF8 IFL (green). The electroporation site, viewed with tdTomato fluorescence (red), has been superimposed on the image of FGF8IFL and appears yellow. An arrow indicates roughly where the FGF8 gradient begins to reverse between the two sources. $\boldsymbol{H}$, Lower magnification of the brain shown in $\boldsymbol{G}$ showing endogenous FGF8 sources in the telencephalon and isthmus (ISO), and ectopic FGF8 in the caudal telencephalon. t, Torso. Scale bars: (in $\mathbf{C} \boldsymbol{A}, \boldsymbol{C}, \boldsymbol{D}, 1 \mathrm{~mm} ; \boldsymbol{B}, 0.7 \mathrm{~mm}$; (in $\boldsymbol{G}) \mathbf{G}, 0.1 \mathrm{~mm} ; \boldsymbol{H}, 0.35 \mathrm{~mm}$.

camera with Axiovision software (Zeiss). A permanent photographic record was kept of each numbered brain and its electroporation site.

Tissue processing. Brains fixed with $4 \%$ paraformaldehyde were sectioned at $20-40 \mu \mathrm{m}$ using a Leica SM2000R sliding microtome and processed for in situ hybridization (ISH) or immunohistochemistry (IHC). P6 pups were perfused transcardially with fixative and immersion-fixed overnight; younger brains were immersion-fixed only. Whole P6 brains were also processed for ISH, as described previously (Grove et al., 1998). cDNAs used to generate riboprobes were $C d h 8$ (a gift from $\mathrm{M}$. Takeichi, RIKEN Center for Developmental Biology, Kobe, Japan), Cuxl (a gift from C. W. Ragsdale, University of Chicago, Chicago, IL), Emx2 (a gift from P. Gruss, University of Göttingen, Göttingen, Germany), Kitl (generated by PCR from mouse cDNA), Rorb (a gift from S. McConnell, Stanford University, Stanford, CA), and Tbr1 (I.M.A.G.E. Consortium, clone W09676). For IHC, primary antibodies used were anti-serotonin transporter rabbit polyclonal antibody (1:2000; ImmunoStar), antiphosphohistone $\mathrm{H} 3$ ( $\mathrm{PHH} 3$; Ser10) rabbit polyclonal antibody (1:200; Millipore), and anti-cleaved caspase 3 rabbit polyclonal antibody (1:200; Cell Signaling Technology). For SERT-IR, dissected cortices were flattened between glass slides in 30\% sucrose/PBS for at least $24 \mathrm{~h}$ at $4^{\circ} \mathrm{C}$ and then sectioned tangentially at $50 \mu \mathrm{m}$ for further IHC processing. Images were captured using a Zeiss Axioscope and Axiocam with Axiovision software. For figures, digital images were adjusted for contrast, color, and brightness using Adobe Photoshop CS4.

Measuring hemisphere area. Sections from both flattened hemispheres of a given brain, one hemisphere electroporated with $F g f 8$ and the other a nonelectroporated control, were processed for SERT-IR. The areas of sections in which all barrel fields of $\mathrm{S} 1$ appeared were measured using ImageJ series 1.4 software $(\mathrm{NIH})$. The areas of paired sections from control and electroporated hemispheres were compared with a paired two-sample $t$ test.

Whisker follicle ablations. Newborn pups (6-20 h old) were anesthetized by hypothermia on ice. Using a stereomicroscope and microdissecting needle-point scissors, a narrow incision was made in the right whisker pad below the whisker follicles to be removed. The upper skin flap of the incision was lifted slightly and the exposed C2 and C 3 or D2 and D3 whisker follicles were removed by grasping the base of the follicles with microdissecting tweezers and pulling the follicles with attached whiskers from underneath the skin flap. The edges of the incision were repositioned together, and the incision was allowed to heal without further manipulation.

Imaging intrinsic signals. Maps of the visuotopic organization of cortex were generated using the phase-encoding mapping procedure described previously (Kalatsky and Stryker, 2003). C57BL/6 mice (2-6 months old) were anesthetized with isoflurane $\left(3-4 \%\right.$ in $\left.\mathrm{O}_{2}\right)$, and body temperature was maintained by a heating pad. Heart rate was monitored to ensure adequate anesthetic level. Mouse heads were stabilized in a stereotaxic apparatus using ear bars. Skin over the dorsal surface of the cranium was incised to provide a view of dorsal cortical areas through the skull, and xylocaine cream was applied to the wound margins. Lowmelting-point agarose ( $3 \%$ in water) was applied to the surface of the cranium, topped by a glass coverslip to produce an optically clear window onto the underlying cerebral cortex. Cortical reflectance was mea- 
sured using a Dalsa 1M30P CCD camera with a custom-built LabVIEW (National Instruments) programmatic interface. The cortical surface was illuminated with $610 \pm 10 \mathrm{~nm}$ light, and reflected light was focused onto the CCD camera using a pair of Nikon lenses $(50 \mathrm{~mm}, \mathrm{f} / 1.4)$ placed face-to-face to produce a macroscope (Bonhoeffer and Grinvald, 1996). Images were captured at a rate of 30 frames per second. Stimuli were generated using the Psychophysics Toolbox (Brainard, 1997; Pelli, 1997) in MATLAB (MathWorks), and were displayed on a 21 inch monitor (P1230; Dell) $23 \mathrm{~cm}$ from the nose of the mouse. The mouse's head was aligned so that the vertical meridian of the animal's visual plane was the vertical centerline of the monitor (see Fig. 9A, red X). Stimuli consisted of a white bar drifting either vertically or horizontally across a black background. A bar completed a single transit across the screen in $6 \mathrm{~s}$ and then started over, repeating 30-80 times. For experiments in which only one eye was stimulated, the other eye was covered. Because the stimuli were periodic, the intensity and phase of responses at the stimulus frequency were related to the strength of neural activity driven by the stimulus and the location of the stimulus on the monitor, respectively. Each pixel in images of cortical responses was color coded to represent the stimulus location that best activated it. Similarly, the brightness of each pixel was used to show how selective the cortical location was to stimulus location. Summary maps therefore represent response selectivity by the brightness of each pixel and the location of the stimulus that best activated the pixel by color.

\section{Results}

Our goal was to determine whether an ectopic source of FGF8, at the right time in neocortical development, could duplicate a complete area map. The mouse area map is complex, with more areas still being characterized (Wang and Burkhalter, 2007). Thus, a set of areas that reaches across most of the mouse neocortex was selected to represent an adequately complete map. These included a complex, central area, S1; a caudomedial area, primary visual cortex (V1); a caudolateral area, primary auditory cortex (A1); and the frontal domain (Fr) that contains primary motor cortex and prefrontal areas (Fig. 1).

New sources of FGF8 were introduced at different sites in the $\mathrm{NP}$ at E10.5, and the neocortical area map was assessed at P6. Several areas can be identified in the neocortex at P6 by expression of genes such as Cuxl and Cdh8 (Fig. $1 B, C$ ), or by SERT-IR (Fig. $1 D$ ). SERT is produced just after birth in axons from sensory relay nuclei of the thalamus that innervate primary sensory neocortex (Lebrand et al., 1996; Brüning and Liangos, 1997; McIlvain et al., 2003). SERT-IR, therefore, not only outlines select areas, but also indicates that they are innervated by the thalamus.

$F g f 8$ and $t d$ Tomato were coelectroporated, and the sites of Fgf8 electroporation were inferred from tdTomato fluorescence in whole P6 brains. Sites of fluorescence were mapped onto a lateral view of a standard P6 brain to estimate the position of the original electroporation site with respect to the R/C and M/L axes of the hemisphere. One hundred P6 brains were selected for efficient electroporation in neocortex and processed for SERT-IR. No preference was given to brains with electroporation sites at a particular location. This approach led to the discovery of strikingly different types of new area patterning corresponding to the $\mathrm{R} / \mathrm{C}$ location of the new FGF8 source.

\section{A far caudolateral source of FGF8 induces a complete duplication of $\mathrm{S} 1$}

Of 100 brains, 24 showed duplications of S1 barrel fields at P6. Duplications included most or all of the posteromedial barrel subfield (pmbsf), the snout barrel field, and the hindlimb (hl), forelimb (fl) and lower jaw (lj) subfields (Fig. 2B-D; data not shown). In endogenous $\mathrm{S}^{1}$, the $\mathrm{hl}, \mathrm{fl}$, and lj fields are rostral to the barrel fields, and the barrel rows of pmbsf (Fig. $2 \mathrm{~A}$, a-e) run
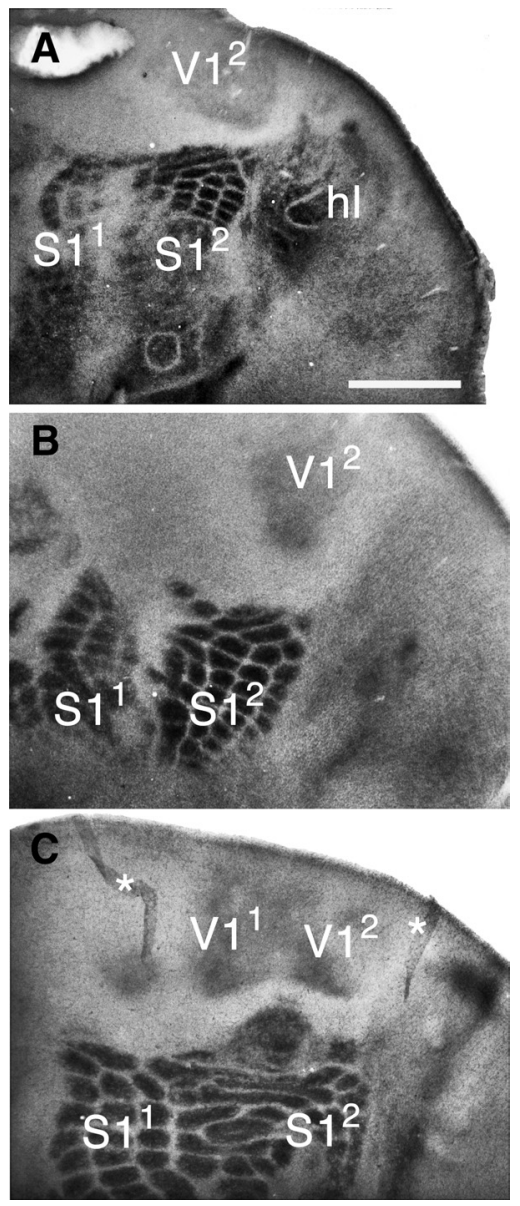

Figure 3. Caudal electroporation of Fgf8 can duplicate V1. A-C, Sections through flattened cortical hemispheres from three brains electroporated with Fgf8 at E10.5 and processed for SERT-IR at P6. In each brain, $\mathrm{S} 1^{2}$ was accompanied by a duplicate of $\mathrm{V} 1\left(\mathrm{~V} 1^{2}\right)$, identified by a moderately intense SERT-immunoreactive triangular domain oriented so that the triangle appears to point to $\mathrm{S}^{2}$ (Fig. 1). In one brain (C), the two S1s have merged extensively, as have the duplicate V1s. Asterisks indicate folded tissue artifacts. Scale bar: (in $\boldsymbol{A}) \boldsymbol{A}, 1 \mathrm{~mm} ; \boldsymbol{B}, 0.8 \mathrm{~mm}$; , $0.6 \mathrm{~mm}$.

approximately caudal to rostral $(\mathrm{C} / \mathrm{R})$; in duplicate $\mathrm{S}^{2}$, the normal R/C configurations were reversed (Fig. 2, compare $A, B-D$ ). Furthermore, in several brains, S1 duplications were accompanied by $\mathrm{V}$-shaped patches of SERT-IR, apparent duplications of $\mathrm{V} 1$ ( $\mathrm{V}^{2}$; Figs. $\left.2 C, 3 A-C\right)$, often partially merged with endogenous V1 (Fig. 3C).

When electroporation sites were charted at P6, the position of the electroporation site in each brain, relative to the induced S1 duplicate, indicated that a new gradient of FGF8 had generated a locally inverted $\mathrm{R} / \mathrm{C}$ axis and that duplicate $\mathrm{S} 1$ was oriented to this new axis (Fig. 2E). Consistent with these observations at P6, in brains electroporated with Fgf8 at E10-E10.5 and collected $24 \mathrm{~h}$ later, FGF8 IFL showed two opposed gradients of FGF8, one emanating from the endogenous source, and the other from the site of Fgf8 electroporation (Fig. $2 G, H ; n=8 / 8$ ).

Electroporation sites that duplicated S1 were clustered in the most caudolateral part of the hemisphere, except for two caudomedial sites (Fig. 2 F). Why should only far caudal sites of FGF8 induce S1 duplicates? Endogenous FGF8 forms a gradient that decays exponentially from its rostromedial source (Toyoda et al., 2010), and ectopic FGF8 similarly generates a declining signaling gradient (Toyoda et al., 2010) (Fig. 2G). The distribution of FGF8 in a brain with two FGF8 sources, therefore, is the sum of two 

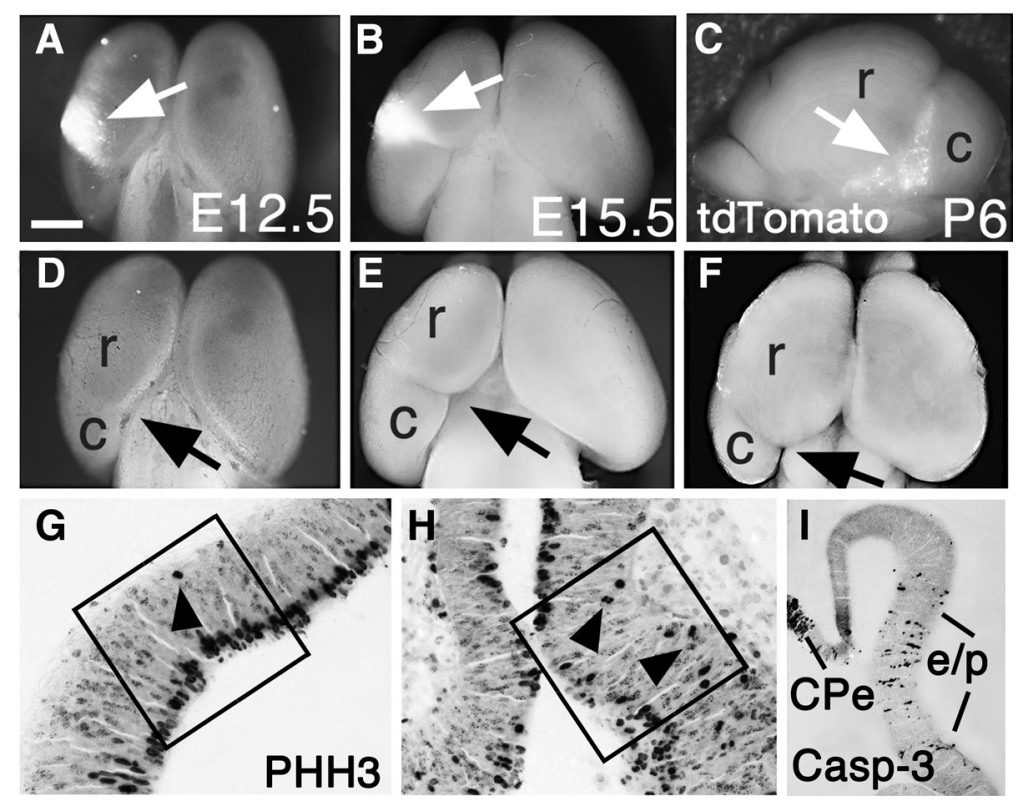

Figure 4. Midlateral electroporation of Fgf8 generates an ectopic sulcus. $\boldsymbol{A}-\boldsymbol{F}$, Whole brains, from a dorsal or lateral $(\boldsymbol{C})$ aspect. Rostral is up or to the left (C). G-I, Coronal sections through E11.5-E12.5 NP; $\boldsymbol{G}$ and $\boldsymbol{H}$ show the control ( $\boldsymbol{G}$ ) and Fgf8-electroporated $(\boldsymbol{H})$ sides of the same brain. $\boldsymbol{A}-\boldsymbol{C}$, Fgf8/tdTomato coelectroporation sites seen by tdTomato fluorescence (arrows). $\boldsymbol{D}-\boldsymbol{F}$, Bright-field images of the same brains shown in $\boldsymbol{A}-\boldsymbol{C}$. The sulcus appears as a slight indentation at E12.5 ( $\boldsymbol{D}$, arrow) and is clear atE15.5 (E) and P6 $(\boldsymbol{F})$, dividing hemispheres into rostral ( $r$ ) and caudal (c) pieces. $\mathbf{G}, \boldsymbol{H}$, Apical mitotic cells form a dense line at the ventricular surface on the control side of an E12.5 brain, but are sparse at the site of sulcus formation in the other hemisphere (compare boxed areas). More basally positioned mitotic cells appear at the site of sulcus formation than in control NP (boxed areas, arrowheads in $\mathbf{G}, \boldsymbol{H})$. I, Coronal section through an E11.5 brain. Caspase-3-IR apoptotic cells are most numerous in the choroid plexus epithelium (CPe), and are also scattered near the site of electroporation (e/p). Scale bar: (in A) $\boldsymbol{A}, \boldsymbol{D}, 0.6 \mathrm{~mm} ; \boldsymbol{B}, \boldsymbol{E}, 1.0 \mathrm{~mm} ; \boldsymbol{C}, \boldsymbol{F}, 2 \mathrm{~mm} ; \boldsymbol{G}, \boldsymbol{H}, 0.04$ $\mathrm{mm} ; \mathrm{I}, 0.075 \mathrm{~mm}$.

gradients (Wolpert, 1978; Summerbell, 1981). As the two sources are brought closer, FGF8 levels in the intervening territory will be high. As they are moved farther apart, intervening FGF8 levels drop (Fig. 2G,H) and show a wider range of concentrations. We suggest that far caudal but not more rostral electroporation of Fgf8 separates the two FGF8 sources sufficiently to allow FGF8 levels to drop to those appropriate for specifying S1.

\section{Specification of different $\mathrm{S} 1$ subfields by different levels of FGF8}

An ectopic caudal source of FGF8 induces a second S1 with subfields reversed along the $\mathrm{R} / \mathrm{C}$ axis, already suggesting that different FGF8 levels specify different subfields. This hypothesis implies that if two sources of FGF8 were positioned closer, the rostral subfields, normally induced by relatively high levels of FGF8, would still be duplicated, whereas more caudal subfields, requiring lower FGF8 levels, might be lost. Supporting the hypothesis, the electroporation sites of three brains (Fig. $2 B-D$ ) are far caudal, midcaudal, and more rostral for Figure $2, B, C$, and $D$, respectively. As would be predicted, $S 1$ subfield duplication is most complete in the brain shown in Figure $2 \mathrm{~B}$; less complete in that shown in Figure $2 C$, where part of the native $S 1$ pmbsf is absent; and least complete in that shown in Figure 2D, in which the caudal pmbsf and snout barrel fields appear merged, but the more rostral hl, fl, and lj subfields are still duplicated. In neither partial map (Fig. 2C,D) were missing barrels evident on sections adjacent to those illustrated. In our sample overall, extreme caudal electroporations (Fig. $2 \mathrm{~F}$, sites beneath blue arrow) induced the most complete S1 duplications, and more rostral electroporations (Fig. $2 \mathrm{~F}$, beneath yellow and green arrows) generated duplications with parts of the caudal subfields missing or fused
(Fig. 2D). These findings are reminiscent of classic studies in which two morphogen sources were grafted into a host limb bud in chick. The number and identity of duplicated digits depended on the distance between the morphogen sources (Summerbell, 1981). In this case, which parts of the S1 body representation were duplicated correlated roughly with the distance between endogenous and ectopic FGF8.

\section{Coordination of patterning and growth}

Organizer signals can coordinate tissue specification and growth (Summerbell, 1981; Agarwala et al., 2001), which would normally help ensure that a specified structure grows to the correct size. When two ZPA organizers were grafted into a chick limb bud, local growth increased, providing room to generate duplicate arrays of digits (Summerbell, 1981). We found that sections from hemispheres with S1 duplicates were, on average, 25\% larger in area than sections from nonelectroporated control hemispheres from the same brains (paired two-sample $t$ test for means, $p=0.002 ; n=7$ brains per group). FGF8-induced growth was correlated with area duplication and electroporation position. Electroporation sites of comparable size to those in Figure 2, but more rostral, did not induce $\mathrm{S} 1$ duplication, and neocortical area measurements were not significantly different from control (paired two-sample $t$ test for means, $p=0.4 ; n=6$ brains per group). These findings suggest that FGF8, to some extent, coordinates neocortical growth and pattern.

\section{A midlateral source of FGF8 induces an ectopic sulcus}

Far caudal electroporation of Fgf8 reliably induced duplications of $\mathrm{S} 1$ and V1, but not A1. Indeed, when caudal Fgf8 electroporation induces a duplicate $\mathrm{S} 1$, the duplicate seems to occupy territory that would otherwise be occupied by A1 (compare Figs. $1 D$, $2 B-D)$. We therefore searched for a condition in which ectopic FGF8 could induce a more complete duplicate map. In the chick embryo, an FGF8-soaked bead inserted into the lateral telencephalon at E2 generates an ectopic sulcus that divides the telencephalon into rostral and caudal vesicles with duplicate structures (Crossley et al., 2001). Following this lead, we examined brains with $F g f 8$ electroporated at central sites along the lateral face of the cortical hemisphere at E10.5 and found that sulci were induced that divided the hemisphere into rostral and caudal sections (Fig. 4A-F). Sulci extended from lateral to medial in neocortex, but did not reach into the depths of the telencephalon, dividing only neocortex, but not hippocampus or ventral telencephalic structures. In effect, as detailed below, the sulci created two neocortical primordia.

An FGF8-induced sulcus was detectable at E11.5-E12.5 and complete by E15.5 (Fig. 4A-F). At E12.5, dividing cells labeled with $\mathrm{pHH} 3$-IR formed a dense line at the ventricular surface (Fig. $4 G$ ), except at the site of a forming sulcus where apical mitoses were selectively decreased (Fig. $4 H$ ). Relatively few basal mitoses were observed at E12.5 (mean, 4; SEM, 0.5; $0.04 \mathrm{~mm}^{2}$ field; sec- 
tions from six control hemispheres; field size equal to boxes in Fig. 4G,H). Close to a forming sulcus, basal mitoses remained low but were significantly increased over control hemispheres (mean, 6; SEM, 0.7; $0.04 \mathrm{~mm}^{2}$ field; paired two-sample $t$ test for means, $p=0.02 ; n=6$; Fig. $4 G, H$, compare boxed areas). This observation suggests that basal progenitor cells were generated prematurely in the latter brains, potentially contributing to sulcus formation. Increased apoptosis was seen near the site of the forming sulcus at E11.5 (Fig. 4I). Consistent with observations in the chick (Crossley et al., 2001), however, apoptosis appeared less likely to play a specific role in sulcus formation, given that ectopic FGF8, even when no sulcus was induced, caused transiently higher levels of cell death (data not shown). Additional study will be needed to identify the precise cellular mechanisms of sulcus formation, which will be challenging given that cell survival shows a nonlinear dependency on FGF8 concentration (Storm et al., 2003, 2006).

Because normal rostral invagination of the telencephalic vesicle occurs close to the endogenous FGF8 source, we and others (Crossley et al., 2001) propose that the ectopic FGF8-induced sulcus resembles the rostral part of the interhemispheric division. To test this possibility, brains in which sulci were just beginning to form were assessed for gene expression patterns characteristic of the entire dorsal telencephalic midline, or selective for the rostral or caudal midline (Fig. 5). As FGF8 induced a sulcus, it induced expression of Zic genes (Zic1, Zic2, Zic3, Zic5; Fig. 5; data not shown), which are expressed throughout the telencephalic midline and associated with its induction (Okada et al., 2008). The forming sulcus also showed Kitl and Fgf15 expression, specific to the rostral telencephalic midline, but not the expression of Wnt and Bmp, genes specific to the caudal midline (Fig. 5; data not shown) (Furuta et al., 1997; Grove et al., 1998; Okada et al., 2008). Consistent with the latter observations, FGF8 has been found to suppress expression of $W n t 3 a$ and $W n t 8 b$ at the dorsal telencephalic midline (Shimogori et al., 2004; Storm et al., 2006). Further suggesting the endogenous rostral source of FGF8 induces the rostral part of the interhemispheric sulcus, brains in which the endogenous source was augmented by rostral Fgf8 electroporation showed expanded domains of Kitl, Zic1, Zic2, Zic3, and Zic5 expression ( $n=9$ of 9 brains with rostral electroporation), confirming and extending a previous report (Okada et al., 2008). Zic transcription factors are candidate key factors of telencephalic midline development (Okada et al., 2008) and have been associated with cell proliferation (Aruga et al., 1998); thus, FGF8 regulation of Zic genes may implicate the latter in the formation of ectopic sulci. Zic genes have multiple roles in neural development (Aruga, 2004); however, and their role here awaits future investigation.

FGF8 induces new maps in the NP caudal to the sulcus

Division of the hemisphere by a sulcus provides an opportunity to test the organizer activity of the new FGF8 source on the relatively naive field of cells caudal to the sulcus. To determine whether ectopic FGF8 at the sulcus initiates R/C patterning in the caudal part of the hemisphere and induces a second area map, we first examined, at E13.5 ( $n=32$ brains), expression of the transcription factor genes Emx2 and Nr2f1, whose high caudal to low rostral gradient is critical for specification of caudal areas (Crossley et al., 2001; Fukuchi-Shimogori and Grove, 2003; Hamasaki et al., 2004; Armentano et al., 2007) and, in particular, sensory cortex (Armentano et al., 2007). In control hemispheres, Emx2 and Nr2f1 were expressed in the expected R/C gradients (Fig. $6 \mathrm{~A}$; data not shown). In hemispheres with sulci, Emx2 and Nr2f1 showed double expression

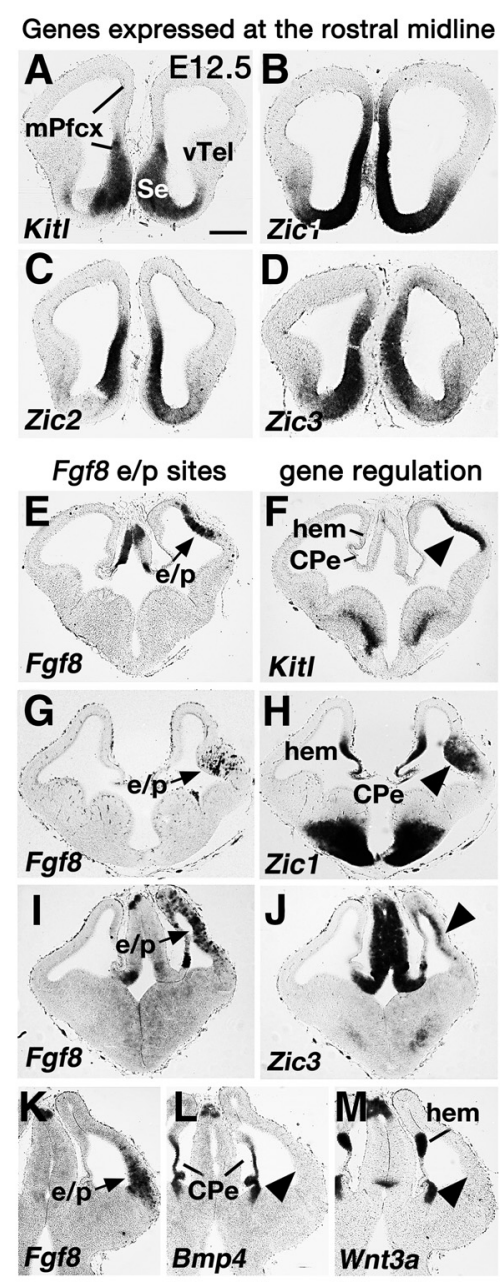

Figure 5. The developing sulcus expresses gene patterns typical of the rostral telencephalic midline. $\boldsymbol{A}-\boldsymbol{M}$, Coronal sections through E12.5 brains processed with ISH for indicated genes. $\boldsymbol{A}-\boldsymbol{D}$, Sections from nonelectroporated control brains. $\boldsymbol{E}-\boldsymbol{M}$, Sections from brains electroporated with Fgf8 at E10.5, processed with ISH to show both normal and ectopic (arrows) Fgf8 expression $(\boldsymbol{E}, \boldsymbol{G}, \boldsymbol{I}, \boldsymbol{K})$, and neighboring sections from the same brains processed with ISH for the genes named $(\boldsymbol{F}, \boldsymbol{H}, \boldsymbol{J}, \boldsymbol{L}, \boldsymbol{M}$; arrowheads indicate sites of electroporation. Kitl (formerly Steel, encoding the $c$-kit ligand) is expressed at the rostral but not caudodorsal telencephalic midline $(\boldsymbol{A}, \boldsymbol{F})$. Zic genes (0kada et al., 2008) are expressed rostrally $(\boldsymbol{B}-\boldsymbol{D})$ and caudodorsally $(\boldsymbol{H})$. Wnt and $B m p$ genes are expressed caudodorsally in the hem and choroid plexus epithelium (CPe; $\boldsymbol{L}$, $\boldsymbol{M}$ ), but not at the rostral midline (Furuta et al., 1997; Grove et al., 1998). Ectopic FGF8 induces expression of Kitl, Zic1, and Zic3 $(\boldsymbol{F}, \boldsymbol{H}, \boldsymbol{J})$ and not Bmp4 and Wnt3a $(\boldsymbol{L}, \boldsymbol{M})$. Inflections in the hemisphere wall (arrowheads) represent the forming sulcus. $\mathrm{mPfcx}$, Medial prefrontal cortex; Se, septum; vTel, ventral telencephalon. Scale bar: (in $\boldsymbol{A}) \boldsymbol{A}-\boldsymbol{D}, 0.2 \mathrm{~mm} ; \boldsymbol{E}-\boldsymbol{M}, 0.4 \mathrm{~mm}$.

gradients. Rostral to the sulcus, Emx2 and $N r 2 f 1$ showed a low rostral, high caudal gradient of expression, as usual. At the sulcus, the site of the new FGF8 source, Emx2 and Nr2f1 expression abruptly lowered, and a second low rostral, high caudal gradient of expression extended from the sulcus (Fig. $6 B, C)$. The double gradients of Emx2 and Nr2f1 support the hypothesis that expression gradients of these genes reflect underlying morphogen gradients of FGF8. Most significant, the native and ectopic sources of FGF8 induced early gene expression patterns consistent with the ultimate development of two area maps.

In several P6 brains, ectopic FGF8 caused neocortex on both sides of the sulcus to adopt features of frontal cortex. Genes that show a characteristic layer pattern in frontal areas at P6 include Tbr1 (Rubenstein et al., 1999) and Kitl. Tbrl is expressed in layer 


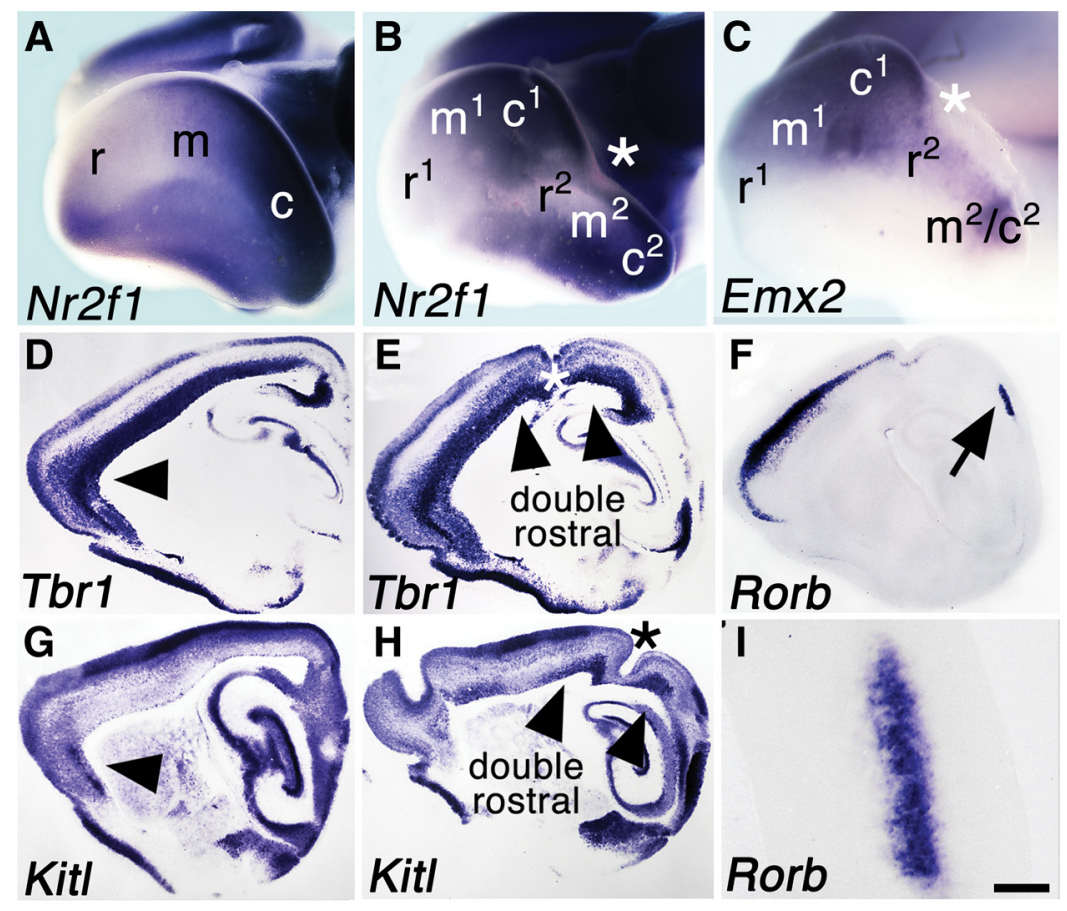

Figure 6. FGF8 at a sulcus generates double gradients of patterning genes and a double rostral identity on either side of the sulcus. A-C, Whole forebrains at E13.5 processed with ISH for the indicated genes. Nr2f1 expression is low rostral to high caudal in control E13.5 hemisphere $(\boldsymbol{A}) . \boldsymbol{B}$ shows $\mathrm{Nr} 2 \mathrm{f1}$ expression in a hemisphere with a forming sulcus (asterisk), with a low to high gradient in the rostral part $\left(r^{1}\right.$ to $\mathrm{m}^{1}$ to $\left.C^{1}\right)$ and second low to high gradient in the caudal part $\left(\mathrm{r}^{2}\right.$ to $\mathrm{m}^{2}$ to $\left.\mathrm{c}^{2}\right)$. Another hemisphere with a forming sulcus (C, asterisk) has double Emx2 expression gradients. $\boldsymbol{D}-\mathbf{I}$, Sagittal sections through control hemispheres $(\boldsymbol{D}, \boldsymbol{G})$ and hemispheres with sulci $(\boldsymbol{E}, \boldsymbol{F}, \boldsymbol{H}, \boldsymbol{I}$, asterisks in $\boldsymbol{E}, \boldsymbol{H})$. Tbr 1 is expressed in all layers in frontal cortex ( $\boldsymbol{D}$, arrowhead) and on both sides of a sulcus ( $\boldsymbol{E}$, double arrowheads). A section adjacent to $\boldsymbol{E}$ reveals secondary $\$ 1$ barrels expressing $R$ orb $(\boldsymbol{F}$, arrow) just caudal to the broad expression of $T b r 1$ in $\boldsymbol{E}$. These barrels are shown at higher magnification in $I$. Strong Kitl expression marks layer 6 of far frontal cortex in a control hemisphere ( $\boldsymbol{G}$, arrowhead) and on both sides of an FGF8-induced sulcus ( $\boldsymbol{H}$, double arrowheads). $r$, Rostral; m, middle; C, caudal. Scale bar: (in I) $\boldsymbol{A}-\boldsymbol{C}, 0.3 \mathrm{~mm} ; \boldsymbol{D}-\boldsymbol{H}, 1 \mathrm{~mm} ; \boldsymbol{I}, 0.15 \mathrm{~mm}$.

2 and deep layers throughout the neocortex, but is additionally expressed in intervening layers in frontal cortex (Fig. 6D); Kitl is expressed strongly in layer 6 of prefrontal cortex (Fig. 6G). In sagittal sections from P6 brains with a sulcus, typically rostral expression of Kitl and Tbr1 appeared on both sides of the sulcus (Fig. $6 E, H ; n=6$ of 6), indicating that FGF8 had induced a double frontal neocortical identity (Fr) on either side. Processing adjacent sections for Kitl/Tbrl and Rorb/Cuxl expression indicated an appropriate relative position for duplicate Fr and S1 (Fig. 6E,F; data not shown); Rorb/Cuxl expression at P6 delineates S1 (Fig. 1; data not shown). These findings suggest that a brain with a sulcus develops two area maps, one in the rostral part of the hemisphere, with possible inverted area duplications, and a second, caudal, normally oriented map.

Confirming this expectation, at P6, SERT-IR revealed secondary area maps in the caudal part of hemispheres with sulci (14 of 20 brains with sulci; Fig. 7C-F). Compared with area duplications induced by far caudal Fgf8 electroporation, duplicate maps caudal to the sulcus were more complete, containing not only S1 and V1, but Al as well, correctly positioned relative to each other and to a new Fr domain (Fig. 7D,F). The Fr domain is not SERT immunoreactive, but could be positively identified in sections from P6 brains, as noted above. Compared with control maps, duplicate area maps were small, but appropriate in size to the tissue available, allocating space to three sensory areas, and oriented to the ectopic FGF8 source as a new rostral telencephalic pole. Thus, ectopic FGF8 organized several developmental steps, including induction of a new R/C axis and appropriate regulation of $E m \times 2$ and $N r 2 f 1$ expression, to specify a new map containing caudal sensory areas and frontal neocortex (Fig. $7 D, F$ ).

New FGF8 sources generated ectopic sulci in 20 of 100 P6 brains processed for SERT-IR. Fgf8 electroporation sites in brains with sulci lay roughly in the central third of the cortical hemisphere (Fig. $7 B$ ). Sites rostral to those illustrated failed to generate a sulcus, and instead enlarged Fr and shifted area boundaries caudally (13 of 100 brains), as observed previously (Fukuchi-Shimogori and Grove, 2001; Sahara et al., 2007).

The strength of ectopic FGF8 signaling determines pattern rostral to the sulcus The piece of NP rostral to the sulcus is subject to two FGF8 sources, one at each end, whose combined signaling could perturb area map development. As expected, in several strongly electroporated brains with sulci ( 7 of 20), the rostral piece of neocortex contained a duplicate, inverted S1 (Fig. 7C,E), as well as portions of the native $\mathrm{S} 1$ (Fig. 7C,E, arrows). In a few brains that were weakly electroporated (4 of 20), however, a standard area map developed in the rostral part of the neocortex (Fig. $8 A, B$ ). In such hemispheres, two maps formed in parallel, with the same $\mathrm{R} / \mathrm{C}$ orientation, on both sides of the sulcus (Fig. 8A-D).

\section{Optical signal imaging reveals visual responses in duplicate $\mathrm{V} 1$}

To discover whether duplicate V1 areas show responses to visual stimuli, we used intrinsic signal optical imaging (ISOI) (Kalatsky and Stryker, 2003) to detect and map visual responses. ISOI follows the changes in light reflectance from the neocortex that result from changes in blood flow and blood oxygenation accompanying neural activity. A separate set of mice was electroporated with $F g f 8$ at E10.5; brains were imaged when the mice were 2-6 months old. The cortical surface was illuminated, cortical reflectance measured through the skull, and images captured and processed as described previously (Kalatsky and Stryker, 2003). For each mouse, the head was stabilized, and white bars, drifting horizontally or vertically across a black background, were presented continuously on a monitor in front of the animal (Fig. $9 A$ ). Because stimuli were periodic, the intensity and phase of cortical responses at the stimulus frequency were related, respectively, to the strength of neural activity driven by the stimulus and the location of the stimulus on the monitor, allowing a visuotopic map of V1 to be generated (Kalatsky and Stryker, 2003) for each imaged, nonelectroporated control hemisphere (Fig. 9C, right). Identifying duplicate V1s in electroporated hemispheres was more challenging. In older brains, tdTomato fluorescence was no longer visible at the electroporation site and could not be used as a guide to whether and where a duplicate V1 might be found. Fortunately, native $\left(\mathrm{V} 1^{1}\right)$ and $\mathrm{V}^{2}$ occasionally lie side by side near the normal V1 position (Fig. 9B). We identified three sets of $\mathrm{V} 1^{1}$ and $\mathrm{V} 1^{2}$ in this conformation showing visual responses. In one example, both $\mathrm{V} 1{ }^{1}$ and $\mathrm{V} 1^{2}$ displayed orderly elevation maps compared with V1 in the control hemisphere (Fig. 9C,D). An- 

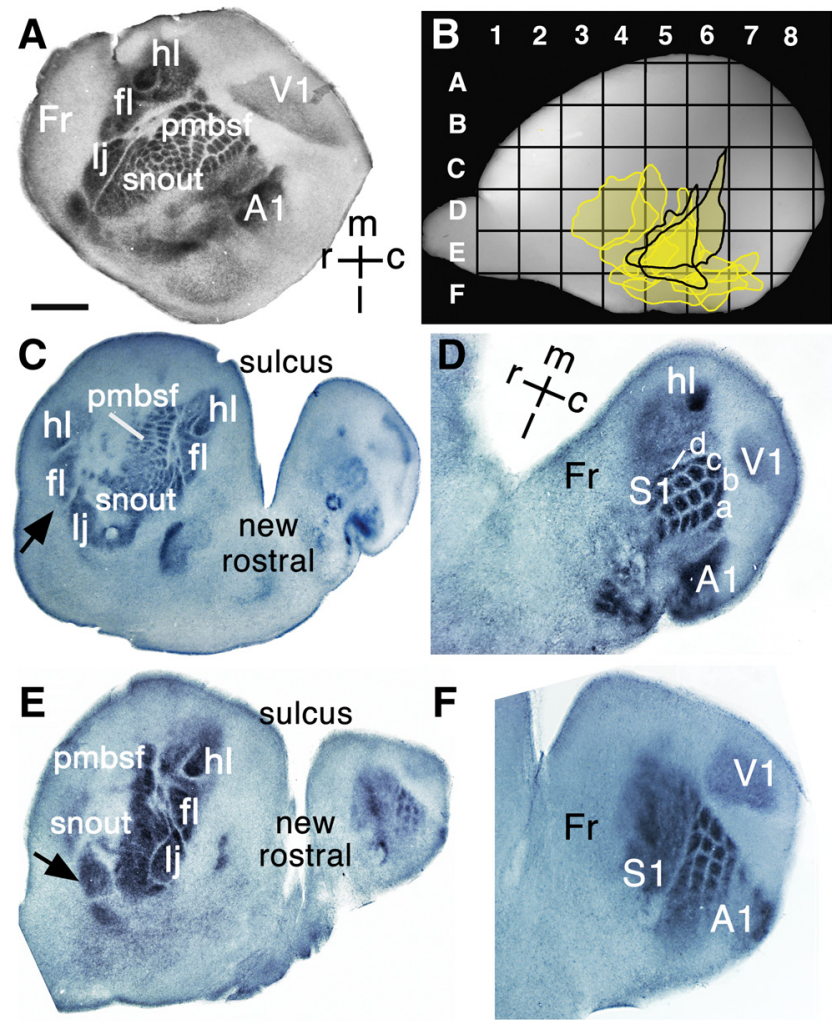

Figure 7. Midlateral FGF8 induces a new area map caudal to the sulcus. $A, C-F$, Sections through flattened P6 cortices stained for SERT-IR. A section from a control hemisphere $(\boldsymbol{A})$ and sections from two brains with FGF8-induced sulci are shown $(\boldsymbol{C}-\boldsymbol{F})$. Sulci reach from lateral to medial in a hemisphere; in sections from flattened cortices, sulci spread wider than appears in whole brains. $\boldsymbol{C}, \boldsymbol{D}$ and $\boldsymbol{E}, \boldsymbol{F}$ are serial sections from the same brains. $\boldsymbol{B}$, Sample of 10 midlateral electroporation sites that induced sulci; sites for the two brains in $\boldsymbol{C}-\boldsymbol{F}$ are outlined in black. Rostral to the sulcus, parts of both native ( $\boldsymbol{C}, \boldsymbol{E}$, arrows) and inverted, duplicate S1s reflect influence of two FGF8 sources. Caudal to the sulcus $(\boldsymbol{C}, \boldsymbol{E})$, duplicate maps appear faintly. $\boldsymbol{D}, \boldsymbol{F}, \mathrm{In}$ sections adjacent to $\boldsymbol{C}$ and $\boldsymbol{E}$, clear caudal, duplicate area maps are seen; $F r, S 1, V 1$, and $A 1$ are distinguished by density of SERT-IR, shape, and relative position (compare $A, D, F$; Fig. 1). r, Rostral; m, middle; c, caudal; l, lateral. Scale bar: (in $A) A, C, E, 1 \mathrm{~mm} ; D, F, 0.5 \mathrm{~mm}$.

other two electroporated hemispheres showed visual responses in both $\mathrm{V} 1^{1}$ and $\mathrm{V} 1^{2}$.

\section{Whisker ablation reveals functional somatotopic input to duplicated $S 1$}

To test for somatotopy in duplicated areas, we returned to $S 1$ to compare responses by native and duplicate areas to functional somatosensory inputs. The barrels of S1 in mice and rats display strong activity-dependent plasticity in the first week after birth. Removing the functional input of specific whiskers in neonates leads to loss of corresponding whisker barrels, often with expansion of neighboring barrels into vacated territory (Van der Loos and Woolsey, 1973; Wong-Riley and Welt, 1980; Jeanmonod et al., 1981). To determine whether duplicate S1 shows the same plasticity, we completely removed the C2 and C3 or D2 and D3 whiskers and whisker follicles in another set of newborn mice that had been electroporated with Fgf8 at E10.5. P6 brains with caudolateral electroporation sites likely to result in duplicated $\mathrm{S} 1$ were processed for SERT-IR. Native S1 showed the expected gap between barrels $\mathrm{C} 1$ and $\mathrm{C} 4$, or D1 and D4, and enlargement of one or more neighboring barrels (Fig. 10D, left; $n=30$ of 31). Strikingly, whenever S1 was duplicated, a matching barrel loss was seen (Fig. $10 D$, right; $n=18$ of 18), demonstrating that duplicate barrel fields respond to functional input and show the
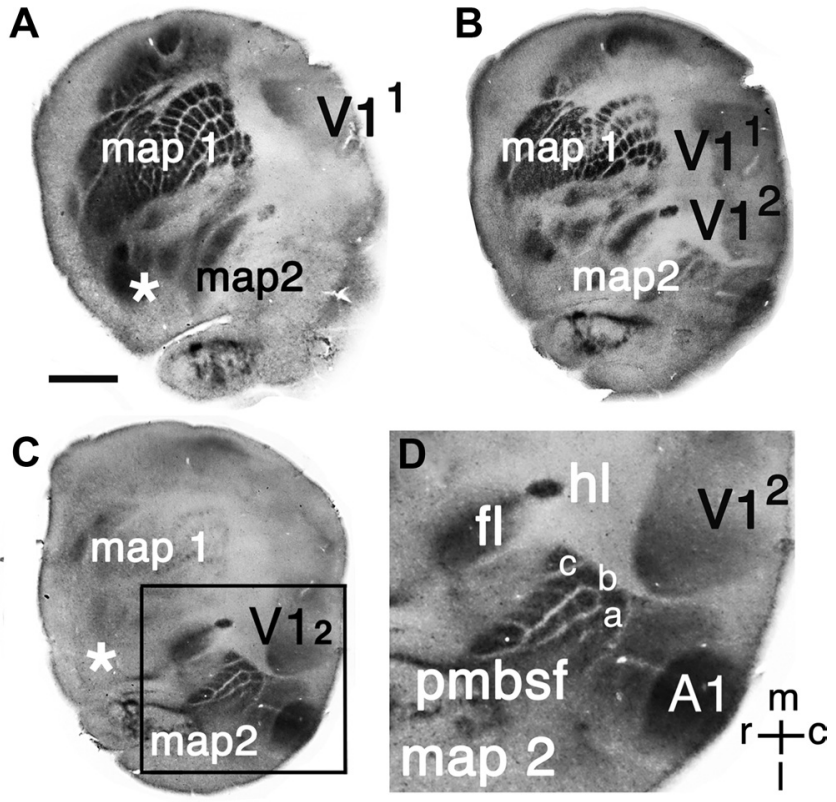

Figure 8. Weak lateral electroporation of Fgf8 leads to two parallel maps. $\boldsymbol{A}$-C, Adjacent sections in serial order through a single flattened hemisphere processed for SERT-IR. $D$ shows a higher magnification of the box in $\boldsymbol{C}$. Asterisks $(\boldsymbol{A}, \boldsymbol{C})$ indicate the position of the electroporation site as identified in whole brain. The hemisphere contains two maps in same $R / C$ orientation. Map 1, most distinct in $A$, is rostral to the sulcus and contains a complete $S 1$ and $V 1$ (V1 $\left.{ }^{1}\right)$. Map 2 in the caudal part of the hemisphere contains a second $S 1, V 1^{2}$, and $A 1$, clearest in $C$ and $\boldsymbol{D} . \mathrm{r}_{\text {, }}$ Rostral; m, middle; c, caudal; I, lateral. Scale bar: (in C) $\boldsymbol{A}-\boldsymbol{C}, 1 \mathrm{~mm} ; \mathbf{D}, 0.4 \mathrm{~mm}$.

same somatotopy as barrels in native $\mathrm{S} 1$. These observations further confirmed that when two sources of FGF8 lie at the opposite poles of a single field of neocortical progenitor cells, the induced duplicate pmbsf is inverted with respect to the native pmbsf along the $\mathrm{R} / \mathrm{C}$ axis. Such mirror-image duplication is expected when two opposing organizers pattern a tissue (Wolpert, 1969; Summerbell, 1979). Here, D-row barrels divide the barrel array asymmetrically, and their ablation therefore provides a forceful image of the inversion of the duplicate barrel field (Fig. 10D).

\section{Discussion}

A new source of FGF8 introduced at the right time and place in the NP can duplicate a V1 that responds to visual stimuli and a complete, inverted S1 that shows evidence of a precise somatotopic representation of the whiskers. Furthermore, a new, midlateral source of FGF8 induces a sulcus that divides the NP into rostral and caudal sectors, and generates an inclusive new map in the caudal part of the neocortex, containing frontal areas, A1, S1, and V1. Our observations imply that FGF8 has organizer activity on a large scale in generating the neocortical area map, and on a fine scale in regulating the somatotopy of $S 1$.

Whenever ectopic FGF8 established a second area map, the map appeared correctly organized along the $\mathrm{M} / \mathrm{L}$ axis. This axis had either already been established when ectopic FGF8 was introduced, or patterning cues continued to establish the $\mathrm{M} / \mathrm{L}$ axis independently. A strong candidate signaling center for the $\mathrm{M} / \mathrm{L}$ axis is the telencephalic roof plate, and subsequently the cortical hem (Grove et al., 1998; Monuki et al., 2001; Grove and Fukuchi-Shimogori, 2003; Cheng et al., 2006), which was present in $F g f 8$-electroporated brains described here (Fig. 5). Thus, R/C and M/L cues continue to coordinate in brains with secondary sources of FGF8.

Three new types of altered area patterning were observed in response to ectopic FGF8 (Fig. 11). Each pattern supports two 

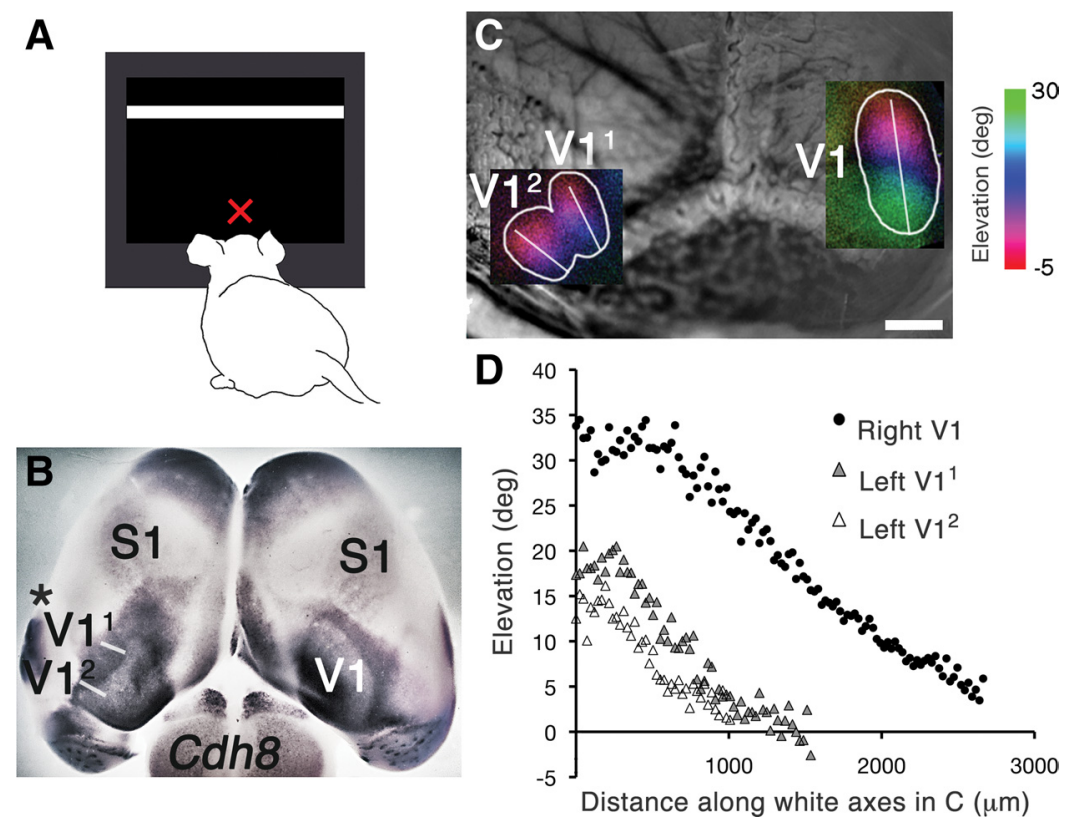

Figure 9. Duplicated V1 shows visual responses. $A$, Horizontal white bars, drifting upward across a black background, displayed on monitor centered in front of the mouse; the red X marks the direction of gaze. $\boldsymbol{B}, \mathrm{P} 6$ forebrain, dorsal view, processed with ISH for Cdh8 expression. The caudolateral sulcus is marked with an asterisk. In a P6 hemisphere, electroporated atE10.5 (left), Cdh8 expression indicates side-by-side V1 ${ }^{1}$ and $V 1^{2}$. C, Caudal cortex electroporated at E10.5, imaged at 3 months with intrinsic signal optical imaging. Left, Electroporated hemisphere shows $\mathrm{V} 1^{1}$ and $\mathrm{V} 1^{2}$ conformation similar to that of the brain shown in $\boldsymbol{B}$. Superimposed on the caudal cortex, color-coded summary maps for visual responses to stimuli presented to the contralateral eye are shown. Color-coding represents bar elevations driving the highest activity in a given cortical location. $\mathrm{V}^{1}{ }^{1}$ and $\mathrm{V} 1^{2}$ in the left hemisphere both show visual responses selective for elevation. $\boldsymbol{D}$, Plot of elevation against distance along axes represented by white lines in $\boldsymbol{C}$; the bottom of the line is zero. Scale bar: in $(\boldsymbol{C})$ $B, 2 \mathrm{~mm} ; C, 1.0 \mathrm{~mm}$.
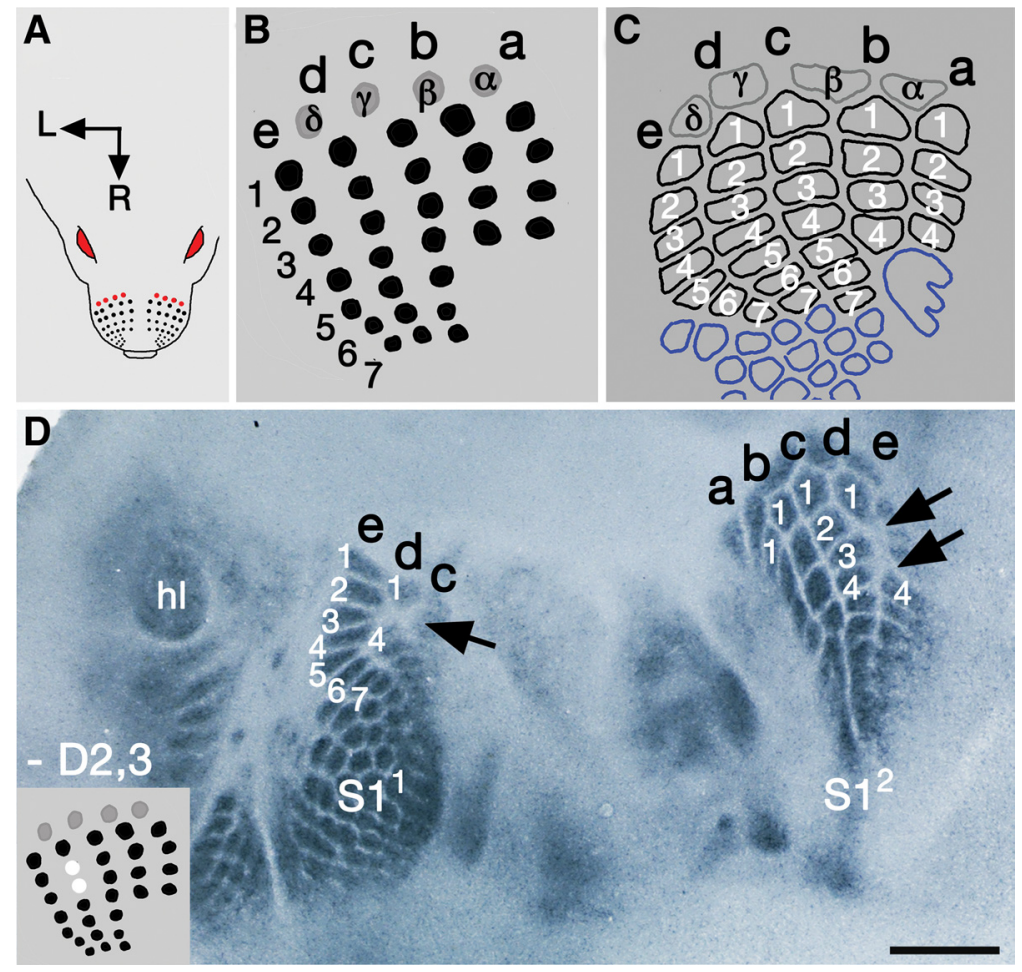

Figure 10. Duplicatebarrels respond to sensory deprivation. $A-C$, Schematics showing rows of large whiskers $(A, B)$ and corresponding barrels in $\mathrm{S1}(\boldsymbol{C})$. Both whisker and barrel rows are labeled ( $\mathrm{a}-\mathrm{e})$. Extra whiskers are red in $A$, or, like corresponding barrels, marked by Greek lettering $(\boldsymbol{B}, \boldsymbol{C})$. Blue shapes $(\boldsymbol{C})$ are barrels representing smaller snout whiskers. $\boldsymbol{D}$, Section through flattened P6 cortex processed for SERT-IR. Fgf8 was electroporated at E10.5 (caudolateral site). A few hours after birth, the mouse's D2 and D3 whiskers were removed (white circles, bottom left insert) contralateral to electroporation site. D2 and D3 barrels are absent in $\mathrm{S1}^{1}$ (left, arrow), and D1 and D4 are slightly enlarged. $S 1^{2}$ (right) also shows loss of D2 and D3 (double arrows), and D1 is enlarged. Scale bar, $0.6 \mathrm{~mm}$. propositions: first, that high levels of FGF8 impart rostral neocortical identity, and second, that a source of FGF8 gives rise to an $\mathrm{R} / \mathrm{C}$ patterning gradient. To produce the first altered area pattern (Fig. $11 B$ ), an ectopic, caudal source of FGF8 creates an FGF8 gradient that is inverted with respect to the endogenous FGF8 gradient. Although the two gradients will overlap, R/C positional values in the hemisphere, roughly speaking, run rostral to caudal, then caudal to rostral (RCCR). S1 and V1 are duplicated, and the duplicates are oriented along the new axis (Fig. $11 B)$. The second pattern, generated by a strong midlateral source of FGF8, is more complex (Fig. 11C). Ectopic FGF8 induces a sulcus that divides the NP into rostral and caudal parts. High levels of FGF8 impart rostral identity to the neocortex on both sides of the sulcus, and new FGF8 gradients form in both rostral and caudal halves of the hemisphere. R/C positional values in this hemisphere therefore run RCCR-RC (the dash here indicating the sulcus). Both native and duplicate areas emerge rostral to the sulcus, whereas caudal to the sulcus, a normally oriented area map develops (Fig. $11 C)$. Notably, in this pattern, there are three full or partial S1 areas, one induced by the endogenous FGF8 source and two others by the lateral source of FGF8 dispersing in gradients on both sides of the sulcus. The third pattern is simpler and is generated by a weaker lateral FGF8 source (Fig. 11D). Again, a sulcus forms, but in this case, ectopic FGF8 has little effect rostral to the sulcus. Two maps form in series ( $\mathrm{R} / \mathrm{C}$ and $\mathrm{R} / \mathrm{C})$. The internal consistency of these induced patterns supports our model, in which an endogenous gradient of FGF8 determines rostral-tocaudal positional values throughout the NP.

Strength of expression of the telencephalic patterning genes Emx2 and Nr2f1, as well as $S p 8$, responds in a dose-dependent way to FGF8 (Storm et al., 2006). Similarly, in the present study, the type of duplicate area map generated depends on the strength of $\mathrm{Fg} 8 \mathrm{8}$ electroporation into the midlateral telencephalon. A weak to moderate secondary FGF8 signal is sufficient to induce a sulcus and to generate a new duplicated map in the caudal part of the NP. A stronger signal is required, however, to compete with the endogenous rostral source of FGF8 and additionally generate inverted, duplicate areas in the rostral part of the NP.

What level of detail in the area map depends on positional information set up by FGF8? We argue that precise positional 

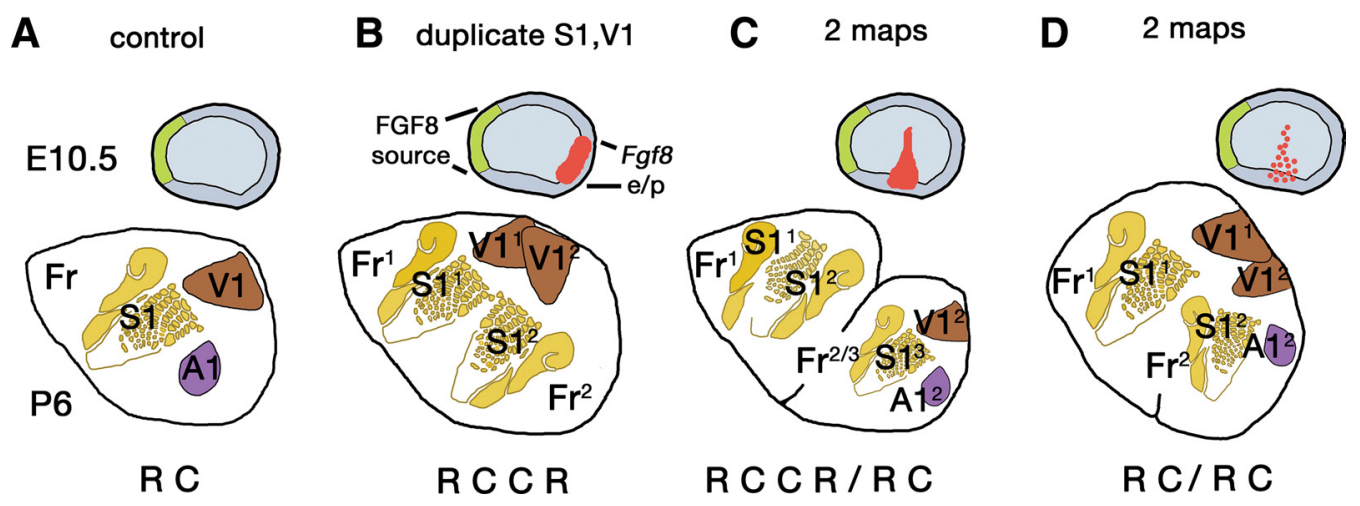

Figure 11. Position and strength of ectopic FGF8 shape new area maps. $\boldsymbol{A}-\boldsymbol{D}$, Top, Schematics of E10.5 control hemisphere $(\boldsymbol{A})$ and hemispheres electroporated with Fgf8 caudally (B) or midlaterally, either strongly $(\boldsymbol{C})$ or weakly $(\boldsymbol{D})$. The endogenous FGF8 source is green; the electroporation site is red. Bottom, Sections through same electroporated brains at P6 (cortices flattened, tangential sections). $A$, Control cortex with normal R/C polarity (RC). B, Caudal FGF8 generates a new R/C axis opposing normal polarity [R/C then C/R (RCCR)]. Native Fr, $\mathrm{S} 1$, and V1 (Fr ${ }^{1}, \mathrm{~S} 1^{1}$, V1 ${ }^{1}$ ) are present, and secondary $\mathrm{Fr}^{2}, \mathrm{S1}^{2}$, and V1 ${ }^{2}$ have been induced. All duplicate areas orient to the new $\mathrm{R} / \mathrm{C}$ axis, most obviously with $\mathrm{S} 1^{2}$. C, Strong midlateral source of FGF8 generates a sulcus. A new rostral ( $\mathrm{Fr}^{2 / 3}$ domain) is induced on either side of the sulcus (RCCR/RC). Rostral to sulcus is native $\mathrm{Fr}^{1}$ and $\mathrm{S} 1^{1}$, and a duplicate, inverted $\mathrm{S} 1^{2}$. Caudal to sulcus is a map containing $\mathrm{Fr}^{3}, \mathrm{~S} 1^{3}, \mathrm{~V} 1^{2}$, and $A 1^{2}$. D, Weak midlateral source of FGF8 allows native and duplicate maps to develop with the same R/C orientation (RC/RC).

information established at the initial stage of neocortical patterning directs progress toward a differentiated area map. For example, a duplicate $S 1$ orients completely toward a new caudal source of FGF8. The relative positions of the main barrel fields and the $\mathrm{hl}$, $\mathrm{fl}$, and lj fields are inverted compared with endogenous $\mathrm{S} 1$, as is the order of pmbsf barrel rows. Moreover, caudal subfields and caudal barrel rows merge between native S1 and duplicate S1 or are lost, when overall FGF8 levels are too high, whereas rostral fields are still duplicated, indicating that rostral and caudal subfields and barrel rows are specified by different concentrations of FGF8. Previous studies demonstrate that the pattern of whiskers supplies the template for whisker representation at each level of the somatosensory pathway, and that functional input from barreloids in the ventral posteromedial thalamus (VPM) to S1 determines whether cortical barrels are present, absent, or added (Van der Loos and Woolsey, 1973; Wong-Riley and Welt, 1980; Jeanmonod et al., 1981; Erzurumlu and Jhaveri, 1990; Iwasato et al., 2000; Ohsaki et al., 2002; Rebsam et al., 2005). We conclude that functional input from VPM to S1 induces barrel formation, but that the pattern of thalamocortical innervation follows an $\mathrm{R} / \mathrm{C}$ axis laid down much earlier by FGF8.

The VPM innervates both native and duplicate S1, with axons dividing and branching in the lower part of the developing neocortex (Shimogori and Grove, 2005). Remaining questions include whether the same axon innervates two duplicate barrels and whether VPM innervation of a larger territory of the cortex, a territory including two S1s, causes development of a larger VPM. As noted, in brains with caudal electroporation of Fgf8, S1 and $\mathrm{V} 1$ can be duplicated, but at the expense of A1 territory. Additional questions, therefore, are whether axons from auditory thalamus degenerate, or terminate elsewhere, and, in either case, whether the auditory thalamus shrinks in consequence.

An FGF8-induced sulcus resembles the rostral part of the fissure between the hemispheres in both mouse (present study) and chick (Crossley et al., 2001), both structurally and by gene expression patterns. In the 100 brains examined at P6, most ectopic sulci formed at central R/C positions in the telencephalic vesicle, although a few formed caudally. No rostral sulci were observed, however, in the 13 brains with electroporation sites confined to the rostral third of the hemisphere. Our inability to induce sulci rostrally may disclose a repressive activity in the rostral telencephalon that prevents high levels of FGF8 from generating more than one rostral sulcus. Evi- dence from the present and previous studies, therefore, indicates that FGF8 has at least three roles in cerebral cortical morphogenesis. First, high levels of FGF8 establish the rostral pole of the cerebral cortex; second, FGF8 induces the rostral part of the interhemispheric fissure; and third, a gradient of FGF8 patterns the neocortical area map along the $\mathrm{R} / \mathrm{C}$ axis.

The isthmic organizer produces FGF8 and patterns the midbrain/hindbrain (Sato et al., 2004). In chick embryos, FGF8coated beads can induce an ectopic isthmic organizer and cerebellum, or, in caudal forebrain, a striking morphological duplication of the midbrain (Crossley et al., 1996; Martinez et al., 1999). Conditional deletion of $F g f 8$ or specific deletion of the FGF8b isoform in mice causes loss of the midbrain, isthmus, and cerebellum (Chi et al., 2003; Guo et al., 2010). Similarly, ectopic FGF8 in the early NP induces neocortical area duplications, and augmenting or reducing the endogenous source of FGF8 causes appropriate R/C area shifts in the map (Fukuchi-Shimogori and Grove, 2001; Garel et al., 2003), including major patterning changes in the frontal cortex immediately adjacent to the endogenous FGF8 source (Garel et al., 2003; Cholfin and Rubenstein, 2008). The rostral telencephalic source of FGF8 appears distinct, at least temporally, from the Fgf8-expressing anterior neural ridge and takes its place with the isthmic organizer among the secondary organizers that pattern the neural tube.

\section{References}

Agarwala S, Sanders TA, Ragsdale CW (2001) Sonic hedgehog control of size and shape in midbrain pattern formation. Science 291:2147-2150.

Armentano M, Chou SJ, Tomassy GS, Leingärtner A, O’Leary DD, Studer M (2007) COUP-TFI regulates the balance of cortical patterning between frontal/motor and sensory areas. Nat Neurosci 10:1277-1286.

Aruga J (2004) The role of Zic genes in neural development. Mol Cell Neurosci 26:205-221.

Aruga J, Minowa O, Yaginuma H, Kuno J, Nagai T, Noda T, Mikoshiba K (1998) Mouse Zicl is involved in cerebellar development. J Neurosci 18:284-293.

Bishop KM, Goudreau G, O’Leary DD (2000) Regulation of area identity in the mammalian neocortex by Emx2 and Pax6. Science 288:344-349.

Bonhoeffer T, Grinvald A (1996) Optical imaging based on intrinsic signals. In: Brain mapping: the methods (Toga AW, Mazziotta JC, eds), pp 55-97. New York: Academic.

Brainard DH (1997) The psychophysics toolbox. Spat Vis 10:433-436.

Brüning G, Liangos O (1997) Transient expression of the serotonin transporter in the developing mouse thalamocortical system. Acta Histochem 99:117-121. 
Chen Y, Mohammadi M, Flanagan JG (2009) Graded levels of FGF protein span the midbrain and can instruct graded induction and repression of neural mapping labels. Neuron 62:773-780.

Cheng X, Hsu CM, Currle DS, Hu JS, Barkovich AJ, Monuki ES (2006) Central roles of the roof plate in telencephalic development and holoprosencephaly. J Neurosci 26:7640-7649.

Chi CL, Martinez S, Wurst W, Martin GR (2003) The isthmic organizer signal FGF8 is required for cell survival in the prospective midbrain and cerebellum. Development 130:2633-2644.

Cholfin JA, Rubenstein JL (2008) Frontal cortex subdivision patterning is coordinately regulated by Fgf8, Fgf17, and Emx2. J Comp Neurol 509:144-155.

Cohen-Tannoudji M, Babinet C, Wassef M (1994) Early determination of a mouse somatosensory cortex marker. Nature 368:460-463.

Crossley PH, Martinez S, Martin GR (1996) Midbrain development induced by FGF8 in the chick embryo. Nature 380:66-68.

Crossley PH, Martinez S, Ohkubo Y, Rubenstein JL (2001) Coordinate expression of Fgf8, Otx2, Bmp4, and Shh in the rostral prosencephalon during development of the telencephalic and optic vesicles. Neuroscience 108:183-206.

Erzurumlu RS, Jhaveri S (1990) Thalamic axons confer a blueprint of the sensory periphery onto the developing rat somatosensory cortex. Brain Res Dev Brain Res 56:229-234.

Fukuchi-Shimogori T, Grove EA (2001) Neocortex patterning by the secreted signaling molecule FGF8. Science 294:1071-1074.

Fukuchi-Shimogori T, Grove EA (2003) Emx2 patterns the neocortex by regulating FGF positional signaling. Nature Neurosci 6:825-831.

Furuta Y, Piston DW, Hogan BL (1997) Bone morphogenetic proteins (BMPs) as regulators of dorsal forebrain development. Development 124:2203-2212.

Garel S, Huffman KJ, Rubenstein JL (2003) Molecular regionalization of the neocortex is disrupted in Fgf8 hypomorphic mutants. Development 130:1903-1914.

Genove G, Glick BS, Barth AL (2005) Brighter reporter genes from multimerized fluorescent proteins. Biotechniques 39:814-822.

Grove EA, Fukuchi-Shimogori T (2003) Generating the cerebral cortical area map. Annu Rev Neurosci 26:355-380.

Grove EA, Tole S, Limon J, Yip L, Ragsdale CW (1998) The hem of the embryonic cerebral cortex is defined by the expression of multiple Wnt genes and is compromised in Gli3-deficient mice. Development 125:2315-2325.

Guo Q, Li K, Sunmonu NA, Li JY (2010) Fgf8b-containing spliceforms, but not Fgf8a, are essential for Fgf8 function during development of the midbrain and cerebellum. Dev Biol 338:183-192.

Hamasaki T, Leingärtner A, Ringstedt T, O'Leary DD (2004) EMX2 regulates sizes and positioning of the primary sensory and motor areas in neocortex by direct specification of cortical progenitors. Neuron 43:359-372.

Huffman KJ, Garel S, Rubenstein JL (2004) Fgf8 regulates the development of intra-neocortical projections. J Neurosci 24:8917-8923.

Iwasato T, Datwani A, Wolf AM, Nishiyama H, Taguchi Y, Tonegawa S, Knöpfel T, Erzurumlu RS, Itohara S (2000) Cortex-restricted disruption of NMDAR1 impairs neuronal patterns in the barrel cortex. Nature 406:726-731.

Jeanmonod D, Rice FL, Van der Loos H (1981) Mouse somatosensory cortex: alterations in the barrelfield following receptor injury at different early postnatal ages. Neuroscience 6:1503-1535.

Kalatsky VA, Stryker MP (2003) New paradigm for optical imaging: temporally encoded maps of intrinsic signal. Neuron 38:529-545.

Lebrand C, Cases O, Adelbrecht C, Doye A, Alvarez C, El Mestikawy S, Seif I, Gaspar P (1996) Transient uptake and storage of serotonin in developing thalamic neurons. Neuron 17:823-835.

Lukaszewicz A, Savatier P, Cortay V, Giroud P, Huissoud C, Berland M, Kennedy H, Dehay C (2005) G1 phase regulation, area-specific cell cycle control, and cytoarchitectonics in the primate cortex. Neuron 47:353-364.

Mallamaci A, Muzio L, Chan CH, Parnavelas J, Boncinelli E (2000) Area identity shifts in the early cerebral cortex of Emx2-/- mutant mice. Nat Neurosci 3:679-686.

Martinez S, Crossley PH, Cobos I, Rubenstein JL, Martin GR (1999) FGF8 induces formation of an ectopic isthmic organizer and isthmocerebellar development via a repressive effect on Otx2 expression. Development 126:1189-1200.

McIlvain VA, Robertson DR, Maimone MM, McCasland IS (2003) Abnormal thalamocortical pathfinding and terminal arbors lead to enlarged barrels in neonatal GAP-43 heterozygous mice. J Comp Neurol 462:252-264.

Miyashita-Lin EM, Hevner R, Wassarman KM, Martinez S, Rubenstein JL (1999) Early neocortical regionalization in the absence of thalamic innervation. Science 285:906-909.

Monuki ES, Porter FD, Walsh CA (2001) Patterning of the dorsal telencephalon and cerebral cortex by a roof plate-lhx 2 pathway. Neuron 32:591-604.

Muzio L, Di Benedetto B, Stoykova A, Boncinelli E, Gruss P, Mallamaci A (2002) Emx2 and Pax6 control regionalization of the pre-neuronogenic cortical primordium. Cereb Cortex 12:129-139.

Nakamura H, Sato T, Suzuki-Hirano A (2008) Isthmus organizer for mesencephalon and metencephalon. Dev Growth Differ 50 [Suppl 1]:S113-S118.

Ohsaki K, Osumi N, Nakamura S (2002) Altered whisker patterns induced by ectopic expression of Shh are topographically represented by barrels. Brain Res Dev Brain Res 137:159-170.

Okada T, Okumura Y, Motoyama J, Ogawa M (2008) FGF8 signaling patterns the telencephalic midline by regulating putative key factors of midline development. Dev Biol 320:92-101.

O'Leary DD, Sahara S (2008) Genetic regulation of arealization of the neocortex. Curr Opin Neurobiol 18:90-100.

Pelli DG (1997) The VideoToolbox software for visual psychophysics: transforming numbers into movies. Spat Vis 10:437-442.

Rakic P (1988) Specification of cerebral cortical areas. Science 241:170-176.

Rebsam A, Seif I, Gaspar P (2005) Dissociating barrel development and lesion-induced plasticity in the mouse somatosensory cortex. J Neurosci 25:706-710.

Rubenstein JL, Anderson S, Shi L, Miyashita-Lin E, Bulfone A, Hevner R (1999) Genetic control of cortical regionalization and connectivity. Cereb Cortex 9:524-532.

Sahara S, Kawakami Y, Izpisua Belmonte JC, O’Leary DD (2007) Sp8 exhibits reciprocal induction with Fgf8 but has an opposing effect on anteriorposterior cortical area patterning. Neural Dev 2:10.

Sato T, Joyner AL, Nakamura H (2004) How does Fgf signaling from the isthmic organizer induce midbrain and cerebellum development? Dev Growth Differ 46:487-494.

Scholpp S, Brand M (2004) Endocytosis controls spreading and effective signaling range of Fgf8 protein. Curr Biol 14:1834-1841.

Shimogori T, Grove EA (2005) Fibroblast growth factor 8 regulates neocortical guidance of area-specific thalamic innervation. J Neurosci 25:6550-6560.

Shimogori T, Banuchi V, Ng HY, Strauss JB, Grove EA (2004) Embryonic signaling centers expressing BMP, WNT and FGF proteins interact to pattern the cerebral cortex. Development 131:5639-5647.

Spemann H, Mangold H (1924) Über induktion von embryonanlagen durch implantation artfremder organisatoren. Roux’ Arch f Entw Mech 100:599-638.

Storm EE, Rubenstein JL, Martin GR (2003) Dosage of Fgf8 determines whether cell survival is positively or negatively regulated in the developing forebrain. Proc Natl Acad Sci U S A 100:1757-1762.

Storm EE, Garel S, Borello U, Hebert JM, Martinez S, McConnell SK, Martin GR, Rubenstein JL (2006) Dose-dependent functions of Fgf8 in regulating telencephalic patterning centers. Development 133:1831-1844.

Summerbell D (1979) The zone of polarizing activity: evidence for a role in normal chick limb morphogenesis. J Embryol Exp Morphol 50:217-233.

Summerbell D (1981) The control of growth and the development of pattern across the anteroposterior axis of the chick limb bud. J Embryol Exp Morphol 63:161-180.

Toyoda R, Assimacopoulos S, Wilcoxon J, Taylor A, Feldman P, SuzukiHirano A, Shimogori T, Grove EA (2010) FGF8 acts as a classic diffusible morphogen to pattern the neocortex. Development 137:3439-3448.

Van der Loos H, Woolsey TA (1973) Somatosensory cortex: structural alterations following early injury to sense organs. Science 179:395-398.

Wang Q, Burkhalter A (2007) Area map of mouse visual cortex. J Comp Neurol 502:339-357.

Wolpert L (1969) Positional information and the spatial pattern of cellular differentiation. J Theor Biol 25:1-47.

Wolpert L (1978) Pattern formation in biological development. Sci Am 239:154-164.

Wong-Riley MT, Welt C (1980) Histochemical changes in cytochrome oxidase of cortical barrels after vibrissal removal in neonatal and adult mice. Proc Natl Acad Sci U S A 77:2333-2337. 